\title{
Advocacy spurs innovation: promoting synergy between physical and biomedical sciences
}

\author{
Susan Samson ${ }^{1,2,3,9^{*}}$, Irene Acerbi ${ }^{1,4,5,10}$, Carole Baas ${ }^{6,11}$, Valerie Weaver ${ }^{1,4,5,7,12}$ and Hope Rugo $3,8,13$
}

\author{
* Correspondence: \\ ssamson@pacbell.net \\ ${ }^{1}$ Bay Area Physical Sciences- \\ Oncology Center, Berkeley, CA, USA \\ ${ }^{2}$ Breast SPORE Advocacy Core \\ (BSAC), Breast Oncology Program, \\ University of California, San \\ Francisco, CA, USA \\ Full list of author information is \\ available at the end of the article
}

\begin{abstract}
Despite dramatic advances in decoding the genes, proteins, and pathways that drive cancer, the disease has evaded the reductionist approaches to defeat it. Recent work has highlighted cancer's heterogeneity, complexity, and ability to develop resistance as major barriers to progress. To better understand and control the processes that govern the initiation, behavior, and progression of cancer, the National Cancer Institute (NCl) created the Physical Sciences-Oncology Center (PS-OC) Network in 2009. As a hub for scientific innovation and as an example of the transdisciplinary research model, the twelve centers within the PS-OC strive for the systematic convergence of the physical sciences with cancer biology. Promoting collaboration between biologists, physicists, mathematicians, chemists, biomedical engineers, and oncologists, the program offers a compelling vision of how new frontiers in physical sciences and oncology will permit the emergence of new scientific principles and opportunities, and of how the benefits of the current convergence revolution would be enhanced by vigorous public/advocacy support.
\end{abstract}

Keywords: Physical sciences, Oncology, Convergence, Advocacy, Transdisciplinary, Collaborative engagement

\section{Background}

Despite dramatic advances in decoding the genes, proteins, and pathways that drive cancer, the disease has evaded the reductionist approaches to defeat it. Recent work has highlighted cancer's heterogeneity, complexity, and ability to develop resistance as major barriers to progress. To better understand and control the processes that govern the initiation, behavior, and progression of cancer, the National Cancer Institute (NCI) created the Physical Sciences-Oncology Center (PS-OC) Network [1] in 2009.

The program brings together leading researchers in the physical sciences and cancer biology in Centers that act as hubs for scientific innovation and the convergence of these two fields. The PS-OCs combine experts from the fields of cancer cell biology and medicine with those from the fields of physics, mathematics, and engineering to focus on four areas: the physics of cancer; de-convoluting complexity; evolution and evolutionary thinking; and information coding and decoding. Within the PS-OC there is a burgeoning belief that the convergence of disciplines will herald a revolution in biomedical research that will permit the emergence of new scientific principles and opportunities.

The program also offers a compelling vision of how the transition from basic research to clinical application requires multidisciplinary expertise and a new transdisciplinary 
collaborative paradigm. Transdisciplinary approaches provide a broad inclusive perspective of science that gives them advantages when measured against the use of multidisciplinary approaches. In the former, stakeholders approach issues through their own disciplinary lens. In the latter stakeholders set aside their certitude and are willing to engage in all sides of an issue; each member is responsible for the whole as they step into each other's roles. Rather than operating in silos, transdisciplinary teams have the flexibility to create and expand upon multidisciplinary collaborations by operating jointly as informative units above and beyond disciplines [2-6].

This commentary draws on the experiences of the Bay Area PS-OC, one of the twelve centers funded by the $\mathrm{NCI}$, and explores the way physical scientists, clinical researchers, and advocates work together in a transdisciplinary setting to optimize innovative and needed paradigm-shifts in breast cancer research and treatment. Focusing on the intersections of mechanobiology research and advocacy involvements, we identify strategies for leveraging collaborative engagement, describe some of the tensions and challenges in the process, consider the implications of such involvements for the conduct of biomedical research, and connect the PS-OC's programmatic work to emerging policy concerns. Ultimately, this is a call to action for the cancer research community. This call to action emphasizes a process for building team collaboration, and it argues for the importance of advocacy integration within transdisciplinary physical sciences and oncology research teams $[7,8]$ to help disrupt the status quo, spur on medical innovation, and reshape the conduct of biomedical research.

\section{$\mathrm{NCl}$ 's message: promote convergence and collaborative engagement in bioscience}

For the past twenty years, breast cancer advocates have been at the forefront of efforts to support and reform translational research processes [9-21]. For example, as champions of evidence based practices, Bayesian statistics, adaptive trial design, biospecimen standardization, biomarker validation, improved test result reproducibility, and informed consent reform, advocates have driven change in research practices as well as in FDA initiatives leading to new regulatory and interpretative mechanisms. Yet, despite their in-depth training, dramatic presence as authors in scientific papers, presenters at scientific conferences, voting members in scientific advisories, cooperative groups, data safety monitoring boards, planning committees, protocol/peer review committees, and informed consent working groups, advocate integration into basic science culture has been limited.

We believe that representing the patient's perspective is easy to do when the studies are clinically focused. It's a bit more difficult with translational work, and it is incredibly challenging when research involves basic science [22]. Bringing transformational change to the PS-OC setting has not been easy because of the prevailing notion that physical sciences research is a relatively autonomous arena with high barriers to entry. Stakeholders have expressed serious concerns about the value of advocacy contribution. How can advocates possibly understand the complex scientific issues under discussion? What exactly is their expertise? What value can they bring to such programs? Why should they be taken seriously?

Advancing the commitment to catalyze synergistic cross-sector interactions to promote convergence in bioscience, the $\mathrm{NCI}$ includes an advocate representative in the administration of the PS-OCs. Under this mechanism, the NCI has clearly sent the message that innovation springs from many sources, not least from advocacy circles and voices. To 
expand the role of the physical sciences in cancer research, the NCI leadership called for a cadre of advocates to both celebrate and offer critical reflection on PS-OC program directions. While in concept a tectonic shift appears to be taking place in the call for advocacy engagement in basic science research programs, it has been a winding road integrating advocates in research processes from inception to implementation. Challenges notwithstanding, The Bay Area PS-OC began establishing formal mechanisms to meaningfully include patient advocates from the outset. And today, most of the twelve centers within the PS-OC Network are attracting talented advocates with the vision and drive to serve as vital catalysts for transdisciplinary innovation.

\section{Advocacy at the interface: Bay Area PS-OC's quest for collaborative engagement}

What happens when you mix the foundations of mechanics with advocacy? What do these two unlikely groups have in common? It turns out that in a shared quest for exciting scientific frontiers, physical scientists, clinical researchers, and advocates work in dynamic symbiotic relationships to accelerate innovative and needed paradigm shifts in cancer research. Convergence goals drive the advocacy sector within the Bay Area PS-OC as follows:

- Determining how tumor microenvironments regulate cancer initiation and behavior through interactions among cell types (e.g., initiated cells, activated stromal cells, and components of the extracellular matrix).

- Originating and testing novel non-traditional physical sciences based approaches to conceptualize, identify, and study the heterogeneity of breast cancer, including the misregulation of multiple pathways related to cell differentiation, cell cycle control, apoptosis, angiogenesis, and the development of metastasis.

- Searching for innovative mechanics-directed clinical interventions that emphasize the importance of the physical organization of cell-to-cell contacts, tissue architecture, tumor microenvironments, and mechanical properties in the response to therapy.

- Evaluating how force, stress, strain, pressure, viscosity, stiffness, and plasticity specifically relate to cellular properties of growth, behavior, and tumor progression.

- Creating novel imaging techniques for studying tumor mechanobiology. The creation of a 3D imaging system will allow scientists to gain a better understanding of how changes in the extracellular matrix contribute to the stiffness of breast tumor tissues.

- Obtaining clinically relevant tissue to model multicellular structures and implement novel image analysis techniques. This is motivated by the true bottom line of moving basic science discoveries from bench to bedside.

- Establishing formal mechanisms with industrial and advocacy partners for moving research discoveries into clinical practice.

Bringing a new focus to transdisciplinary engagement, we spotlight how advocacy transforms the Bay Area PS-OC Center's research landscape. The Bay Area PS-OC focuses on the mechanobiology of tumor progression in breast cancer, and consists primarily of researchers from UC Berkeley, UC San Francisco, the Lawrence Berkeley National Lab, the Helen Diller Family Comprehensive Cancer Center, and the California 
Institute of Quantitative Biosciences. The Center's research explores new approaches that take into account spatiotemporal dynamics, membrane architecture, the tumor microenvironment, and the genomic, physical, and clinical aspects of tumor heterogeneity [7] ${ }^{a}$. Drawing guidance from a rich legacy of government-sponsored cancer research programs promoting collaborative engagement $[23-27]^{\mathrm{b}}$, advocates play a pivotal role in overall team composition. Participating in four areas: 1) research and programmatic support, 2) education and outreach, 3) policy and strategy, and 4) representation and advisory, trained advocates bring unique perspectives to the research decision making process as they join stakeholders in shaping new programmatic directions.

Applying four core principles that forge synergy with NCI Advocacy Research Working Group Recommendations: strategic innovation, collaborative execution, evidence based decision-making, and ethical codes of conduct [28], researchers and advocates interact across a broad spectrum of partnership modes at various levels of intensity.

Five major goals and the mechanisms or tactics by which advocates have established their credibility are summarized below:

Goal 1: Engage the wisdom/perspectives of advocates in the initial and final stages to review grants, vet hypothesis, define strategic priorities, address research challenges, and encourage disruptive change in the interests of anticipating the needs of patients and saving lives. Advocates are serving in unprecedented ways in the Bay Area PS-OC's basic science programs. Although there are many types of advocacy engagements (e.g., educational, political, community outreach, fundraising), we use the term "advocate" developed by the NCI Office of Advocacy Relations to define representatives who bring a non-scientific viewpoint to the research process and communicate a collective patient perspective [18]. Advocating on behalf of the patient, they have become powerful non-traditional allies who focus on the values of identity and patient empowerment. As cultural brokers, advocates provide a face to researchers, highlighting the human element associated with cancer research. As end-users, advocates lend a unique dimension to cancer conversations with their laser focus on translational research. And, as translators, advocates communicate the researcher perspective to patients in a non-technical way and provide feedback to the PS-OC regarding public perceptions of the PS-OC. For instance, prior to submitting a grant, advocates comment on whether the composition of investigators, themes, or approaches within a given PS-OC seem to be logical-- thus identifying problems that are actually intrinsic to the program, or problems with the public face of the program that could be fixed through its presentation. Always respecting the scientific imperative, they address hurdles and bottlenecks in research processes, help establish formal mechanisms for moving highly technical evidence-based agendas into clinical practice, and thereby advance their own strategic goals within science.

Goal 2. Incentivize the participation of advocates to attend and present at local seminars, external site review committee presentations, and national PS-OC meetings. Investing themselves in the research culture, advocates attend and present at Annual NCI PS-OC's Network Investigator's Meetings and participate in programmatic committees, lectures, monthly dinner meetings, and ad hoc involvement in research projects. In addition, researchers will continue to support oncology-specific classes, creating educational resources to be developed into a "cancer boot camp" for physical sciences students and advocates. 
Goal 3. Partner with advocates to link the philosophy, goals, and vision of the PS-OC with external scientific, clinical, and advocacy audiences. To encourage science literacy and communicate the implications of a mechanics-centric view of cancer with external scientific, clinical, and advocacy audiences, advocates attend and present at local and national scientific meetings. For example, as PS-OC program representatives advocates give voice to the importance of physical sciences approaches in oncology at scientific meetings (e.g., Specialized Program of Research Excellence in Breast Cancer, American Association for the Advancement of Science, American Association for Cancer Research, Susan G. Komen for the Cure, San Antonio Annual Breast Cancer Symposium, American Society for Clinical Oncology, and Partnering for Cures, among others).

Goal 4. Create new pathways for the translation and dissemination of information. To distill the message of science, advocates assist in developing and disseminating materials such as fact sheets and lay abstracts. These materials explore, for example, the implications of the tumor microenvironment, metastatic colonization, and evolutionary thinking in cancer initiation and progression, as well as the clinical applicability of the Center's powerful new detection and intervention strategies for breast cancer. Moreover, as lay consultants, advocates catalyze dialogue between science, oncology, and advocacy communities about convergence in biomedical research, contribute to the PS-OC national newsletter, and offer technical assistance to inform all stakeholders (scientists, clinicians and advocates) within the broader PS-OC Network about relevant policy issues in establishing advocacy integration within programs [29]. Moving forward, advocates will leverage new social

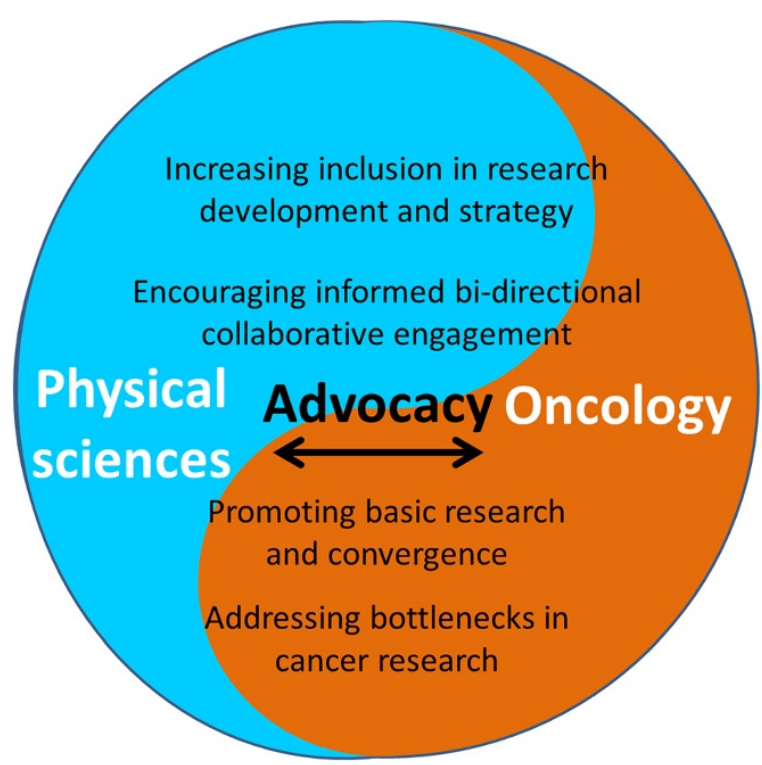

Figure 1 Bay Area PS-OC's Advocates Advancing Bioscience Initiatives (AABI). The Bay Area PS-OC's $\mathrm{AABI}$ is the embodiment of NCl's commitment to promote convergence in bioscience. The diverse engagement activities embrace the connection between physical sciences approaches, oncology, and advocacy to address barriers in cancer control. Importantly, the platforms highlight the value of lay participation in heralding a revolution in biomedical research. As vital catalysts for transdisciplinary innovation, advocates synthesize, prioritize, and give voice to three important aims: increasing the inclusion in the initial and the final stages of research development and strategy, encouraging informed bi-directional stakeholder engagement, and reducing the cultural barriers that impair communication. 
media technology (e.g., cell phone applications, blogs, drop boxes) to engage, inform, and disseminate research results regarding the importance of physical sciences approaches to advance innovation in cancer research.

Goal 5: Democratize expertise: promote bi-directional mentoring programs. The Bay Area PS-OC's Advocates Advancing Bioscience Initiative (AABI) (Figure 1) is a team science effort focused on promoting bi-directional science advocacy exchange. Advocates influence and shape research design, practice and policy by offering guidance in harnessing the next generation of young investigators. And direction in developing a more systematic analysis of what is working and what is not in the myriad of collaboration activities.

\section{Optimizing team collaboration}

Collaborative team science provides a starting point for comprehensive change. Drawing inspiration from the team initiatives proposed by the National Heart, Lung, and Blood Institute (NHLBI), part of the National Institutes of Health (NIH), and the National Institute of Environmental Health Sciences, U.S. Department of Health and Human Services, we commend a way for all stakeholders to develop dynamic reciprocal relationships in which they set priorities jointly [30,31]. In our view, some of the most exciting opportunities for collaborative engagement lie at the intersection of disciplines (Figure 2) when all stakeholders collectively identify approaches and strategic processes that point to:

\section{Synergies of interest}

Championing the development of transdisciplinary leadership, innovative disruption, and new fields of study that converge perspectives and approaches of physical sciences and

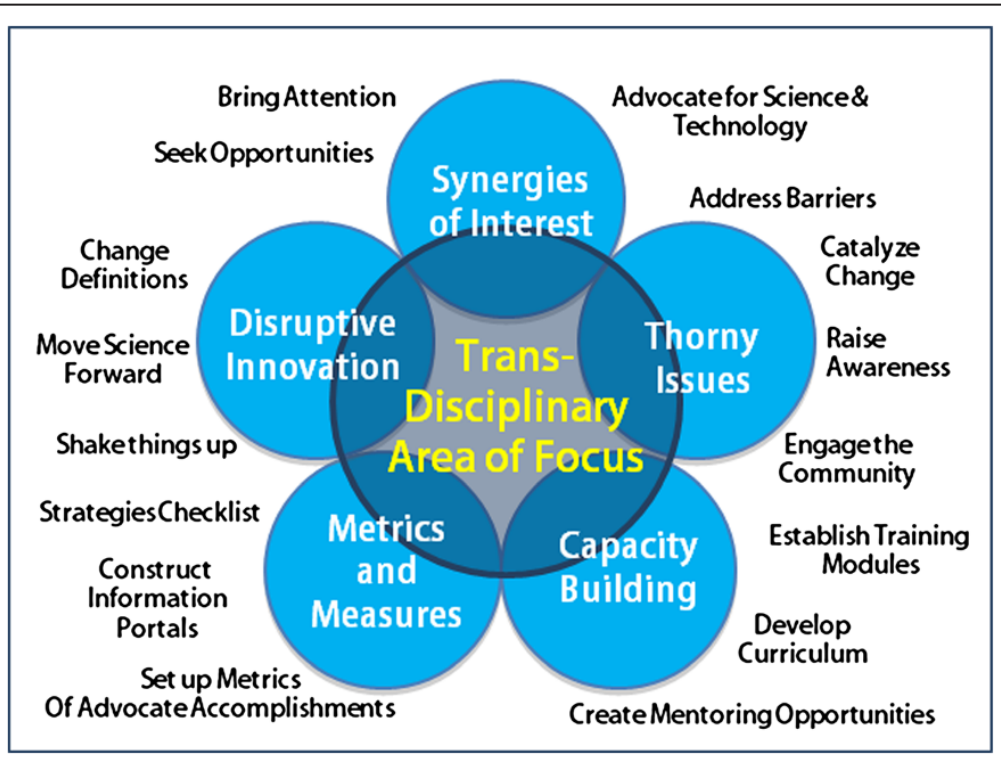

Figure 2 Key Elements of the Bay Area PS-OC collaboration model. Innovation in cancer and biomedical research will originate from collaboration within and between related and unrelated disciplines. Some of the most exciting engagement lies at the intersection of disciplines when all stakeholders (scientists, clinicians, and advocates) collectively consider new approaches and strategic process that point to synergies of interest, thorny issues, capacity building, metrics and measures, and new engagement models. 
engineering with cancer biology, clinical oncology, and advocacy lay expertise, Bay Area PS-OC clinicians, scientists and advocates are pushing the envelope for specific changes in the way we think and talk about cancer research processes. Advocates join physical scientists in advancing innovative non-traditional high impact science that puts new emphasis on the cause and prevention of cancer based upon mechanics, systems, evolutionary, and biological factors. Supporting novel methods for clinical detection and imaging, as well as therapeutic agent discovery and oncogene resistance solutions, they promote the importance and consequent benefits to society of physical science approaches.

\section{Solutions to bottlenecks}

Working in transdisciplinary teams, advocates catalyze change in research practices by identifying systematic barriers to research efficacy, effectiveness, and expediency. For example, as noted in the concluding section of this commentary, advocates have developed sophisticated strategies for working within the system, yet they plan to demonstrate the power of public activism by taking sides in pre-existing disputes regarding deadline thinking campaigns. Although advocates have no jurisdiction over established scientific terrain, they are garnering "advisory jurisdiction" through their engagements, and they are hopeful that the broader impact of their public activism will lead to shifts in the balance of power between competing visions of how convergence should be promoted in biomedical science.

\section{Capacity building programs}

To sharpen and shape the vision for training and mentoring opportunities, the Center's Outreach and Education taskforce has created educational training workshops, retreats, and modules to formalize the scientific training of advocates and sensitize researchers regarding the advocacy engagement process. As PS-OC researchers rethink their potential alliances with advocates as sources of innovation, they ask: How will this become an appropriate role for the NCI to play? What resources does the NCI currently have to support these programs? What other programs or infrastructure initiatives are needed? What approaches or management tools are available to lead the way? And importantly, how can the advocacy community apply lessons from prior advocacy successes to effect change in the PS-OC research paradigm?

Teamwork in science is a critical component of our Bay Area PS-OC's success. To foster bidirectional collaboration and facilitate leadership development, advocates, clinicians and scientists have sought to move out of their comfort zones to identify best practices for transdisciplinary engagement. For example, to build the capacity of young scholars to more effectively communicate their science and develop the translational potential of their projects, Valerie Weaver, the Bay Area PS-OC co-director, encouraged Irene Acerbi, a biomedical engineer and postdoctoral researcher studying the mechanical properties of human breast tissue, to assemble a mentor committee composed of senior researchers in biology and clinical sciences, along with trained members of the research advocacy community. Representing the advocate perspective, Susan Samson, Linda Vincent, and Hannah Klein Connolly helped Irene in grantsmanship by discussing the significance and impact of the project from the patient's perspective. During the development of the project, advocates will receive periodic progress reports and will be invited to lab meeting presentations and workshops about the nanotechnology techniques that Irene uses to study breast 
cancer tissue samples in the project. Advocates will participate in the discussion of the project progress and results. As vital catalysts for transdisciplinary innovation, advocates will provide researchers with new perspectives on problem solving, offer insights to guide the review of research proposals, and discuss strategies to mobilize science into sound translational and policy solutions.

\section{Metrics and assessment tools}

To assess the processes and dynamics that contribute to successful collaboration [31], and to gauge performance, we ask vital questions: Who is doing what, and how well are they doing it? How will advocates be valued, recognized, and rewarded as members of academic committees and advisories? Will advocates have the leeway to present their visions for change in research design, practice, policy, and infrastructure? Will advocates be viewed as limited partners if they challenge the system and take action against the status quo? Will there be a place in this partnership for dissent, and how should stakeholders negotiate their differences? Moreover, in setting up metrics and assessment tools to evaluate how advocates impact the research, we are developing information portals to allow for the exchange of ideas, suggestions, recommendations, and best practices.

In building a culture of team science that promotes advocacy collaboration, we are guided by two questions: how can advocacy contribute to the systematic convergence of the physical sciences with cancer biology, and how can advocacy spur biomedical innovation? To define the metrics of our success, we have recently created a task force comprised of a diverse group of advocates, senior researchers, young investigators, and clinicians. This task force is designed to help all stakeholders apply logic models developed by the National Institute of Environmental Health Sciences (NIEHS) and create a toolkit that can facilitate science advocacy engagements. A cross section of scientists, clinicians and advocates from the University of California San Francisco (UCSF) Breast Oncology Program (BOP) and NCI-sponsored SPORE and PS-OC programs will gather to challenge conventional wisdom about the value of science advocacy inputs, activities, outputs and impacts. Topics for discussion will include, elements of a successful framework for researcher advocate engagements, challenges to achieving goals, suggestions for strengthening and sustaining collaboratives, and key entities to guide infrastructure improvements.

Taskforce members will develop recommendations regarding:

- Priorities: What are the top three priorities for researcher advocate engagement based on the BOP scope, and its importance to the engagement effort?

- Short-term goals: What are the top three opportunities that are realistic shortterm goals for improving the productivity and effectiveness of our interactions?

- Long-term goals: What are the long-term goals that we need to identify and meet?

- The value of bidirectional research stakeholder engagement: How do we build on an agenda that reflects the critical thinking of diverse stakeholder groups, (a) senior research investigators, (b) clinicians, (c) post-doctoral researchers, (d) advocates.

We should learn from these exchanges what mechanisms are actually working or failing, and employ best practices more widely. 


\section{New engagement models}

Looking to models of innovative partnering outside the academic establishment, we are struck by the way the industry investor conference model is employed to provide structured opportunities to bring together people who have the same interests across sectors. We are also impressed by the way nonprofit foundations, with their abiding interest in promoting translational research agendas, are ideally positioned to encourage disruptive innovative partnering strategies and collaborations. As noted by Faster Cures CEO, Margaret Anderson, "Venture philanthropy groups are now being looked at as the shining example of how a strategic mindset mixed with entrepreneurialism, tenacity and a relentless focus on outcomes can be applied to figure out the best way to do something that can lead to systems change across all sectors" [32]. For example, the Biomarker Consortium of the Foundation for the NIH collaborated with Quantum Lead Healthcare Collaborative to sponsor I-SPY 2, an adaptive breast cancer trial design in the setting of neoadjuvant chemotherapy. Examining the importance of the microenvironment for the response to therapy and utilizing an efficient, innovative clinical trial process, it shortens the time expected for a promising agent to complete Phase III studies, gain regulatory approval, and become part of routine care. Importantly, this trial involves more advocates in a greater variety of ways than previous trials and represents an exciting new paradigm for Phase II assessment of investigational agents and testing of associated biomarkers [33].

\section{Discussion}

\section{The broader impact of advocacy for convergence}

As new frontiers in oncology evolve, advocates have an important role to play in basic research as credible knowledge brokers and agents of change [34-38]. Embracing the PS-OC imperative "think boldly and creatively", challenge the status quo, consciously break down the silos that impair collaboration, advocates support researchers in the conduct of precision-based, patient-centered, ethically responsible research that brings attention to the emergence and behavior of cancer based on a unifying physical sciences-based thematic approach. For example, catalyzing dialogue between science, oncology, and patient communities, advocates share the hope that integrating sophisticated molecular biology with the physics of transport throughout the body will offer greater precision in the diagnosis and treatment of breast cancer as a heterogeneous disease. Advocates communicate to patients the potential of new tools such as tensile force analysis, collagen crosslinking analysis, and computational models based on tissue mechanics. As scientists pull together a story line with a focus on the genome linking targeted medicine, personalized therapy and emerging drug resistance, advocates appreciate the critical role of mechanical force and the microenvironment as regulators of cell signaling. Furthermore, advocates promote optimism that combination treatments targeting both the mechanical properties of the tissue and the cells will become a viable approach to enhancing therapeutic efficacy.

Yet, despite the looming excitement for these transformative approaches, advocates are keenly aware of a nagging paradox: promoting convergence in bioscience offers a path toward innovation in both cancer prevention and therapeutics that does not always have immediate clinical implications. To some extent, the elephant in the room is not the experimental or technical elegance of the science, but the future of basic 
cancer research. In an era where NIH financial support is constrained and advocacy organizations are reluctant to fund the work unless the project has imminent translational promise, there is concern that the dogma challenging the basic research needed to move the cancer field forward will not be funded in this climate.

Refusing to sit at the research table as liminal bystanders [37], advocates draw upon lessons from HIV/AIDS [39,40] and breast cancer activist efforts [36] as they question basic assumptions regarding the benefit of deadline campaigns. Individual outspoken advocates are shifting the discourse to emphasize that unrealistic targets promoted by researchers and mainstream advocacy organizations [41,42] have simultaneously become a call to action and a double-edged sword for stakeholders who wish to end cancer. Certainly patients await and increasingly demand a cure for cancer. But at what cost? Deadline thinking is not a prudent choice when science dictates a different path forward. It is not the definitive measure for driving the discovery and innovation needed to solve the cancer puzzle [43].

\section{Conclusions}

We are at a pivotal crossroads in the convergence of science, medicine and advocacy. Yet, change is difficult and challenges remain. In the pursuit of collaborative frontiers in physical sciences research, scientists within the Bay Area PS-OC realize that they have strong and supportive partners in advocates. As members of transdisciplinary collaborative teams, advocates can help expedite scientists' strategic goals.

So how are we collectively trying to bring meaningful change to the system? Recognizing that time is ticking for the patient, and that accountability exists to translate findings into practical applications [44], we argue for a new funding model that balances priorities for clinical trials and faster cures with realistic objectives and timetables/milestones for completion. Moreover, we share the sincere hope [45] that to facilitate progress, we must continue to make a strong case for the growth of federal and philanthropic support, the reform of peer review processes evolving from the intersection of disciplines, the reform in the epistemic practices of biomedical research, as well as evaluation efforts identifying progress in transdisciplinary team science and advocacy collaboration.

Why is this important? In 2010, when NCI director Harold Varmus announced plans to accelerate NCI research, he suggested that we are entering a new era of scientific discovery and innovation in bioscience. By asking researchers to pose and address a series of provocative questions, he implicitly urged all to remember that patients need answers, better precision medicine, better prevention, and better early detection.

The time is right to forward the new opportunities for revolutionizing convergence in biomedical science. And, when researchers across the national PS-OC Network answer this call to action, they can be confident that engaging a cadre of convergence-oriented advocates as vital catalysts and authentic partners in transformative physical sciences research efforts will help advance medical innovation, democratize science, and expedite the incredible potential of future investments in bioscience.

\section{Endnotes}

a The Bay Area PS-OC's research efforts are divided into three Projects. Project 1 is "Fundamental Mechano-Chemical Signaling of Cancer," headed by Jay Groves and 
including Frank McCormick and Clair Tomlin. Project 2 is "Mechanobiology of Acinar Stability," headed by Valerie Weaver and including Hana El-Samad, Sanjay Kumar, and Gerard Marriott. Project 3 is "Dynamics in the Tissue State-Space: From Normal to Tumor and Back," headed by Jan Liphardt and including Mina Bissell, James Sethian, Dan Fletcher and Sylvain Costes. Outreach and Education efforts are led by Hope Rugo and including Saheli Datta.

b The Translational Research Program (TRP) is the home of the SPOREs - the Specialized Programs of Research Excellence - a cornerstone of NCI's efforts to promote collaborative, interdisciplinary translational cancer research. SPORE grants involve both basic and clinical/applied scientists and support projects that will result in new and diverse approaches to the prevention, early detection, diagnosis and treatment of human cancers. Information about the NCI Selected Programs Of Research Excellence (SPORE) is available at the website: http://trp.cancer.gov/.

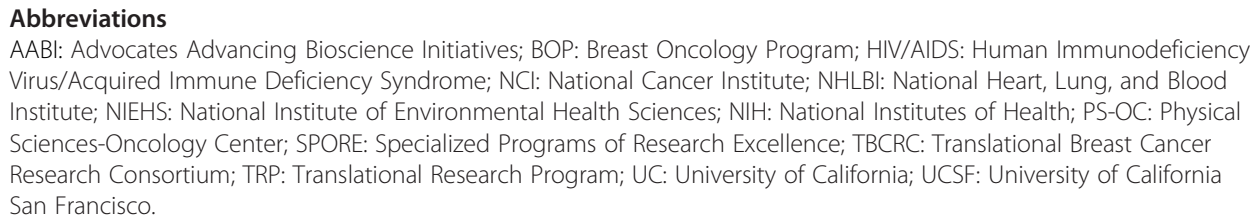
Virus/Acquired Immune Deficiency Syndrome; NCl: National Cancer Institute; NHLBI: National Heart, Lung, and Blood Institute; NIEHS: National Institute of Environmental Health Sciences; NIH: National Institutes of Health; PS-OC: Physical Sciences-Oncology Center; SPORE: Specialized Programs of Research Excellence; TBCRC: Translational Breast Cancer Research Consortium; TRP: Translational Research Program; UC: University of California; UCSF: University of California San Francisco.

\section{Competing interests}

I declare that the authors have no competing interests as defined by EPJ Nonlinear Biomedical Physics, or other interests that might be perceived to influence the results and/or discussion reported in this article. A full disclosure signed by each author will be sent upon request.

\section{Authors' contributions}

SS drafted the manuscript, and spearheaded its design and coordination. IA, CB, VMW and HR made substantial contributions in drafting the manuscript and revising it critically for important intellectual content. All authors read and approved the final manuscript.

\section{Acknowledgments}

We would like to acknowledge all the members of the UCSF Breast Oncology Program, Breast SPORE Advocacy Core (BSAC) for their support and give special thanks to Linda Vincent, Hannah Klein Connolly, Susie Brain, Diane Heditsian, Janice Barlow, and Bambi Schwartz, BSAC members; Yekaterina Miroshnikova, PS-OC scholar, Jane Perlmutter, I- SPY 2 lead advocate, Sanford Jeames, American College of Imaging Radiology Network (ACRIN) advocate, Robert Hiatt, UCSF Department of Epidemiology and Biostatistics, Professor and Chair, UCSF Helen Diller Family Comprehensive Cancer Center, Deputy Director and Director, Population Sciences, Nicole Moore, NCI PS-OC Project Director, Jonathan Franca-Koh, NCI PS-OC Project Manager, Joe Alper, Life Science and Nanotechnology Consulting, Michelle Bennet, NHLBI Deputy Scientific Director, Kristianna Pettibone, Health Science Administrator NIH/NCl, Anna Barker, former NCI Deputy Director, Sarah Goins, UCSF Breast Oncology Program Analyst, and Laura Van 'T Veer, UCSF Breast Oncology Program Principal Investigator, for their input, and editing of the content presented in these comments and/ or a companion poster. Finally, special thanks to Judith Brown for her careful reading and editing of many drafts. This work was supported by grant U54CA143836-01 from the NCI to VMW and JL, and PDF12230246 Susan G Komen Breast Cancer Foundation Postdoctoral Fellowship to IA.

\section{Disclaimer}

The content of this article is solely the responsibility of the authors and does not represent the official views of the National Cancer Institute or National Institutes of Health.

\footnotetext{
Author details

${ }^{1}$ Bay Area Physical Sciences-Oncology Center, Berkeley, CA, USA. ${ }^{2}$ Breast SPORE Advocacy Core (BSAC), Breast Oncology Program, University of California, San Francisco, CA, USA. ${ }^{3}$ Helen Diller Family Comprehensive Cancer Center, San Francisco, CA, USA. ${ }^{4}$ Department of Surgery, University of California, San Francisco, CA, USA. ${ }^{5}$ Center for Bioengineering and Tissue Regeneration, University of California, San Francisco, CA, USA. ${ }^{6}$ PS-OC, Office of Physical Sciences-Oncology, National Cancer Institute (NCI), Bethesda, MD, USA. D.pepartments of Anatomy and Bioengineering and Therapeutic Sciences, and Member, Eli and Edythe Broad Center of Regeneration Medicine and Stem Cell Research, University of California, San Francisco, CA, USA. ${ }^{8}$ Breast Oncology and Clinical Trials Education, Bay Area PS-OC Educational and Outreach, University of California, San Francisco, CA, USA. ${ }^{\text {Bay }}$ Area Physical Sciences Oncology Center (PS-OC), Breast Oncology Program, UCSF Helen Diller Family Comprehensive Cancer Center, UCSF, Box 1710, San Francisco, CA 94143-1710, USA. ${ }^{10}$ Department of Surgery, UCSF, Center for Bioengineering \& Tissue Regeneration, Bay Area PS-OC, 513 Parnassus Avenue, room HSE560, San Francisco, CA 94143-0456, USA. ${ }^{11}$ Office of Advocacy Relations, National Cancer Institute, Office of Physical Sciences/Oncology National Cancer Institute, $\mathrm{NCl}$ Office of
} 
Physical Sciences-Oncology (PS-OC), Building 31, Room 10A03, 31 Center Drive, MSC 2580, Bethesda, MD 20892-2580, USA. ${ }^{12}$ Departments of Surgery, Anatomy \& Bioengineering \& Therapeutics, UCSF, Director, Center for Bioengineering \& Tissue Regeneration, 513 Parnassus Avenue, room HSE560, San Francisco, CA 94143-0456, USA. ${ }^{13}$ Breast Oncology and Clinical Trials Education, Lead, Bay Area PS-OC Educational and Outreach, UCSF Helen Diller Family Comprehensive Cancer Center, Box 1710UCSFm, San Francisco, CA 94143-1710, USA.

Received: 4 February 2013 Accepted: 9 May 2013

Published: 9 May 2013

\section{References}

1. Information about the Physical Sciences Oncology Centers Network is available through the National Cancer Institute, Center for Strategic Scientific Initiatives. website at: nci.physics mail.nih.gov.

2. Information about the Cancer Center Support Grant Guidelines and the Cancer Centers program. available at: http://cancercenters.cancer.gov/.

3. Rosenfeld PL: The potential of transdisciplinary research for sustaining and extending linkages between the health and social sciences. Soc Sci Med 1992, 35:1343-57.

4. Hiatt RA, Haslam ZS, Osuch J: The breast cancer and the environment research centers: Transdisciplinary research on the role of the environment in breast cancer etiology. Breast Cancer and the Environment Research Centers Environmental Health Perspectives 2009, 117(12):1814-22.

5. Gehlert S, McClintock M, Conzen S, Olufunmilayo O: The Importance of Transdisciplinary Collaborations for Understanding and Resolving Health Disparities. Soc Work Public Health 2010, 25:408-422.

6. Osuch JR, Silk K, Price C, Barlow J, Miller K, Hernick A, Fonfa A: A historical perspective on breast cancer activism in the United States: from education and support to partnership in scientific research. J Womens Health 2012, 21:355-362

7. Datta S: Bay Area PS-OC Self Profile. National Cancer Institute Physical Sciences in Oncology Perspectives 2011, 2:4-6.

8. Dusheck J: Physical scientists take on cancer. Nature 2012, 491:S49-S67.

9. Information about Project LEAD of National Breast Cancer Coalition. available at the website at: http://www.stopbreastcancer.org.

10. Information about advocacy training at the San Antonio Breast Cancer Symposium. available at: http://www.alamobreastcancer.org and www.sabcs.org

11. Information about the Survivor and Patient Advocacy Program at the American Association for Cancer Research. available at: http://www.aacr.org.

12. Information about the Advocate Program at the American Association for Clinical Oncology. available at: http://www.asco.org.

13. Information about Komen Advocates in Science is available through Susan G. Komen for the Cure. website at: http://www.komen.org

14. Information about the trainings offered by the Research Advocacy Network. available at: http://www.researchadvocacy.org.

15. Information about the trainings offered by Genetic Alliance. available at: http://www.geneticalliance.org

16. Information about the website trainings offered by Cancer Information Services Network. available at: http://www.cisncancer.org.

17. Information about Kay Dickersin, Ph.D. and Musa Mayer's tutorial, "Understanding Evidence-Based Healthcare: A Foundation for Action". available on the website: http://us.cochrane.org.

18. Information about the Office of Office of Advocacy Relations is available through the National Cancer Institute. website: advocacy.cancer.gov.

19. Information about the U.S. Food and Drug Administration (FDA) Consumer Advisory Committee. available on the FDA website: https://www.fda.gov/AdvisoryCommittees.

20. Information about the Department of Defense (DOD) Breast Cancer Research Program (BCRP). available on the Department of Defense website: http://cdmrp.army.mil/berr.

21. Information about the California Breast Cancer Research Program (CBCRP). available on the website: http://www.cbcrp.org.

22. Baas C: The Role of the Advocate: Helping Unravel the Complexity of Cancer. National Cancer Institute Physical Sciences in Oncology Perspectives 2010, 1:17-18.

23. Information about the NCI Specialized Programs Of Research Excellence (SPORE). available at the website: http://trp cancer.gov/.

24. Perlmutter J: Advocate Involvement in I-SPY 2. Breast Diseases: A Year Book Quarterly 2011, 22:21-23. Further information about the I SPY 2 Advocacy Program is available at the website: http://www.gemini-grp.com.

25. Information about the Translational Breast Cancer Research Consortium (TBCRC). available at the website: https://www.web.emmes.com/study/bcrc/.

26. Silk KJ, Neuberger LB, Nazione SA, Ousch J: The Breast Cancer and the Environment Research Centers: a transdisciplinary model. In Contemporary Issues in Health Communication: Theoretical and Practical Case Studies. Edited by Quesry J, Brann M. New York: Springer Publishing; 2010.

27. Information about the Bay Area Breast SPORE Advocacy Core is available on the UCSF. website: cancer.ucsf.edu/research/breast-spore/breast-cancerspore-advocacy-core.

28. Office of Advocacy Relations at the National Cancer Institute, U.S. Department of Health and Human Services, National Institutes of Health: Advocates in Research Working Group Recommendations; 2011 available at the website: deainfo.nci.nih.gov/advisory/dcig/ARWG-recom.pdf.

29. Samson S: Bay Area Physical-Sciences in Oncology Center (PS-OC) Advocacy Forward: Move It! National Cancer Institute Physical Sciences in Oncology Perspectives 2012, 1:16-17.

30. Bennett ML, Gadlin H, Levine-Finley S: Collaboration and Team Science: A Field Guide. 2010. Available at the website: http:///teamscience.nih.gov. 
31. Drew HC, Pettibone KG, Anderson B, Beard SD, Davis HL, Dilworth CH, O'Fallon L, Collman GW: Partnerships for Environmental Public Health Evaluation Metrics Manual. National Institute of Environmental Health Sciences, U. S. Department of Health and Human Services: $2012 \mathrm{NIH}$ Publication No. 12-7825.

32. Information about Faster Cures, The Center for Accelerating Medical Solutions, and their blog. available on the website: http://wwwfastercures.org.

33. Information about The Biomarkers Consortium and QuantumLead Healthcare. available on the websites: http://www.biomarkersconsortium.org and http://www.quantumleaphealth.org.

34. Dresser R: When science offers salvation: patient advocacy and research ethics. New York: Oxford University Press; 2001

35. Mayer M: A Seat at the Table: A Research Advocate's Journey. Journal of Participatory Medicine 2009, 1(1):e14.

36. Collyar D: How Have Patient Advocates in the United States Benefited Cancer Research? Nat Rev Cancer 2005, 5:73-78.

37. Mayer M: Patient Advocacy in Research Merely an Afterthought? Patient 2011, 4(2):69-71.

38. Thompson J, Bissell P, Cooper C, Armitage CJ, Barber R: Credibility and the 'professionalized' lay expert: Reflections on the dilemmas and opportunities of public involvement in health research. Health (London) 2012, 16(6):602-18

39. Epstein S: The construction of lay expertise: AIDS activism and the foregoing of credibility in the reform of clinical trials. Science, Technology, \& Human Values 1995, 20:408-437.

40. Manganiello M, Anderson M: Back to Basics: HIV/AIDS Advocacy As A Model for Catalyzing Change. Strategists and Faster Cures and HCM Strategists 2011:1-27. available on the website: www.hcmstrategists.com/ contenBack2Basics_HIV_AIDSAdvocacy.pdf

41. Information about the National Breast Cancer Coalition's 2020 deadline challenge can be gleaned from their website. http://www.breastcancerdeadline2020.org/about-nbcc/.

42. ScienceDaily (Sep. 21, 2012): Information about Moon Shots program. available at the website: http//cancermoonshots.org/

43. Nature. Misguided cancer goal. 2012, 491:637 doi:10.1038/4916379.

44. Collins FS: Reengineering translational science. The Time is right. Sci Transl Med 2011, 3:1-6.

45. Sharp PA, Langer R: Promoting Convergence in Biomedical Science. Science 2011, 333:527.

doi:10.1140/epjnbp1

Cite this article as: Samson et al: Advocacy spurs innovation: promoting synergy between physical and biomedical sciences. EPJ Nonlinear Biomedical Physics 2013 1:1.

\section{Submit your manuscript to a SpringerOpen ${ }^{\circ}$ journal and benefit from:}

- Convenient online submission

- Rigorous peer review

- Immediate publication on acceptance

- Open access: articles freely available online

- High visibility within the field

- Retaining the copyright to your article

Submit your next manuscript at $\boldsymbol{~ s p r i n g e r o p e n . c o m ~}$ 